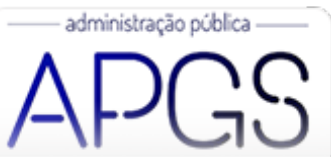

Administração Pública e Gestão Social ISSN: 2175-5787

apgs@ufv.br

Universidade Federal de Viçosa

Brasil

\title{
Difusão dos Organismos de Políticas para Mulheres nos governos municipais: análise dos determinantes da política (1998-2014)
}

Walter Costa, Maria Luiza; Bandeira Coêlho, Denilson

Difusão dos Organismos de Políticas para Mulheres nos governos municipais: análise dos determinantes da política (1998-2014)

Administração Pública e Gestão Social, vol. 12, núm. 1, 2020

Universidade Federal de Viçosa, Brasil

Disponible en: http://www.redalyc.org/articulo.oa?id=351561601009

Esta obra está bajo una Licencia Creative Commons Atribución-NoComercial-SinDerivar 3.0 Internacional. 


\title{
Difusão dos Organismos de Políticas para Mulheres nos governos municipais: análise dos determinantes da política (1998-2014)
}

\begin{abstract}
Diffusion of Organisms for Women's Policies in municipal governments: analysis of policy determinants (1998-2014)

Difusión de los Organismos de Políticas de Mujeres en los gobiernos municipales: análisis de los determinantes de la política (1998-2014)
\end{abstract}

Maria Luiza Walter Costa

Instituto de Ciências Sociais, UnB, Brasil

Redalyc: http://www.redalyc.org/articulo.oa?

mluizawc@gmail.com

Denilson Bandeira Coêlho

Universidade do Texas em Austin, Brasil

denilsonbc@unb.br

id $=351561601009$

Recepción: 27 Febrero 2018

Aprobación: 05 Abril 2019

Publicación: 01 Enero 2020

\section{Resumo:}

Quais fatores determinam a difusão de políticas para mulheres no Brasil? Este artigo visa explicar o processo de adoção do Organismo de Políticas para as Mulheres (OPM) em cerca de 700 municípios entre 1998 e 2014. A análise utiliza as bases teóricas dos estudos de difusão e testa a relevância tanto dos determinantes internos quanto externos sobre o comportamento político do executivo local. Para além da dimensão política como competição eleitoral e ideologia, a pesquisa testa a influência de fatores específicos no caso, como a posição dos gestores e o papel da Secretaria de Políticas para as Mulheres da Presidência da República (SPM-PR). Os principais resultados confirmam que a SPM-PR e os partidos políticos tiveram papel indutor na difusão do OPM. Surpreendentemente, a influência da capital foi maior do que a do próprio governo estadual nos demais municípios do estado.

PALAVRAS-CHAVE: Implementação, agenda social, inovação institucional, comportamento político.

\section{Abstract:}

What are the factors determining the diffusion of women's policies in Brazil? The objective of this article is to explain the process of diffusion of the Organism for Women's Policies (OPM) in approximately 700 local governments, between 1998 and 2014 . This analysis uses the theoretical base of diffusion studies and tests the relevance of internal and external determinants to explain the decision made by local governments. Beyond the political dimension as electoral competition and ideology, this research tests the influence of specific factors related to gender area, like the role played by political managers and the inductive role of the federal Secretariat for Women's Policies. The main results confirm that the Secretariat for Women's Policies and the political parties strongly influenced the diffusion of the Organism for Women's Policies. Surprisingly, the capital's influence was higher when compared to the state government one, in other local governments.

KEYWORDS: Implementation, social agenda, institutional innovation, political behavior.

\section{ReSUMEN:}

¿Qué factores determinan la difusión de políticas para mujeres en Brasil? Este artículo pretende explicar el proceso de adopción del Organismo de Políticas para las Mujeres (OPM) en cerca de 700 municipios entre 1998 y 2014 . El análisis utiliza las bases teóricas de los estudios de difusión y prueba la relevancia tanto de los determinantes internos y externos sobre el tema comportamiento político del ejecutivo local. Además de la dimensión política como competencia electoral e ideología, la investigación prueba la influencia de factores específicos al caso como la posición de los gestores y el papel de la Secretaría de Políticas para las Mujeres de la Presidencia de la República (SPM-PR). Los principales resultados confirman que la SPM-PR y los partidos políticos tuvieron un papel inductor en la difusión del OPM. Sorprendentemente, la influencia de la capital fue mayor que la del propio gobierno estatal en los demás municipios del estado.

Palabras ClaVe: Implementación, agenda social, innovación institucional, comportamiento político. 


\section{INTRODUÇÃO}

No período mais recente observa-se um avanço na agenda governamental no que se refere a políticas públicas para mulheres no Brasil. A maior participação das mulheres na população economicamente ativa (Instituto de Pesquisa Econômica Aplicada [IPEA], 2010), o incremento no acesso a políticas de seguridade social e a aplicação de legislações específicas como a Lei Maria da Penha têm minimizado a desigualdade de gênero no país (Fórum Nacional de Organismos Governamentais de Políticas para as Mulheres, 2014), entretanto, outras questóes de natureza política e social persistem, como a baixa representatividade das mulheres nos parlamentos, a discrepância de rendimentos com os homens no mercado de trabalho formal e o incremento dos índices de violência.

Diante de tal quadro, qual tem sido a resposta do Estado? Como o sistema político tem avançado em termos da adoção de novas ideias e soluções? Em um contexto de avanço na agenda pública, algumas inovações institucionais têm chamado a atenção dos policy makers. Mais recentemente a experiência dos Organismos de Políticas para as Mulheres (OPM) se disseminou por várias regiões do país. Esses organismos são instituições responsáveis pela elaboração, coordenação, articulação e execução de políticas para mulheres. Tais instituições são assim denominadas de maneira ampla porque possuem variação quanto aos objetivos e estrutura de funcionamento. Até o final de 2014, 695 municípios e 25 unidades federativas haviam adotado o OPM em seus territórios. O aspecto central que chama a atenção é que o OPM tem sido objeto de crescente interesse por municípios marcadamente distintos em termos políticos, administrativos e socioeconômicos. A exemplo de outros programas inovadores ${ }^{[\mathrm{i}]}$, as taxas de adoção dos organismos são fragmentadas, mas crescentes no tempo, o que evidencia que o fenômeno não é um processo automático de cópia típico da descentralização federativa. Com base nestas características, a investigação apresenta um arcabouço teóricoconceitual centrado nos estudos de difusão que privilegiam uma análise comparativa com a aplicação de métodos mistos. Por meio de um mapeamento histórico do processo, o intuito é contribuir com a literatura para compreender em que condições uma inovação recente impacta o sistema federativo.

Para cumprir seus objetivos o estudo aplicará algumas das vertentes das teorias de difusão que fundamentalmente são úteis para explicar por que e como políticas surgem e se disseminam no tempo. A literatura de difusão vem sendo desenvolvida, sobretudo, pela ciência política norte-americana e europeia. Nos Estados Unidos, os principais temas tratados são a adoção de políticas públicas entre os governos estaduais (Walker, 1969; Collier \& Messick, 1975; Berry \& Berry, 1990; Mintrom, 1997; Shipan \& Volden, 2006), inovações de taxas e impostos (Berry \& Berry, 1992), reformas administrativas (Peters, 1997) e novas legislações de proteção ao cidadão (Pacheco, 2012; Boushey, 2016). Mais recentemente, estudos sobre a interdependência internacional entre países em temas diversos passaram a receber mais atenção (Gilardi, 2012; Maggetti \& Gillardi, 2014; Brooks, 2015; Gonnet, 2015). Na literatura nacional, a academia tem focado o fenômeno da difusão de programas de transferências de renda condicionada, reformas sociais no setor de saúde e ações de controle (Sugiyama, 2008; Coêlho, 2012; Coêlho et al., 2016, Batista, 2017), além dos programas de orçamento participativo e do papel do Brasil como exportador de políticas públicas (Wampler, 2008; Spada, 2009; Faria, 2012; Oliveira, 2013). No período atual a agenda tem destacado temas como o federalismo (Couto et al., 2018), governança (Pereira et al., 2018) e transferência de instrumentos de políticas (Howlett, Ramesh, \& Saguin, 2018).

Análises das ações governamentais sobre a temática de política para mulheres correlacionada com a influência de variáveis políticas, sociais e institucionais e o comportamento do executivo são ainda raras tanto em âmbito internacional quanto no contexto doméstico. Com foco na tomada de decisão do executivo municipal, este artigo intenta compreender o processo de difusão dos Organismos considerando um conjunto de fatores que influenciaram os governos locais. Além dos atributos internos das unidades, são também considerados na análise fatores intrínsecos ao caso, como o sexo da liderança política, a influência da 
capital e do governo estadual e o papel da Secretaria de Políticas para as Mulheres da Presidência da República (SPM-PR). Nessa perspectiva, o estado da arte do presente estudo foi construído para descrever e analisar por que e de que forma inovações como o OPM se disseminam no sistema político nacional. A contribuição ao debate é centrada no pressuposto que novos programas públicos dependem de um conjunto de fatores de natureza política, institucional e social para serem adotados. Portanto, não é ojetivo do artigo desenvolver uma análise sobre o histórico da agenda de políticas para mulheres ou sobre os resultados do OPM.

$\mathrm{O}$ artigo apresenta a seguinte estrutura de análise. Uma revisão da literatura informa os principais fundamentos conceituais das teorias de difusão. Em seguida são delimitados os aspectos metodológicos, hipóteses e variáveis. A próxima seção contextualiza o surgimento e a disseminação do modelo OPM para identificar a distribuição geográfica do programa. A seção analítica ilustra os fatores determinantes do processo de difusão da política. A conclusão demonstra a validade do construto teórico aplicado e os resultados da pesquisa.

\section{Literatura de Difusão de Políticas}

As teorias de difusão buscam analisar o fenômeno da adoção de inovações políticas por um grupo de governos de um determinado sistema político ou a replicação de modelos internacionais entre países. Os inventários de Graham, Shipan e Volden (2008) e Shipan e Volden (2012) evidenciam que nas últimas cinco décadas cerca de 1000 artigos trataram da disseminação de políticas públicas, revelando a grande importância da abordagem para as ciências sociais.

Nos anos 1960, dois autores centrais lançaram as bases teóricas e conceituais da literatura de difusão. As contribuições de Everett Rogers e Jack Walker oportunizaram uma futura agenda de pesquisa na literatura internacional. Rogers (1995) elaborou o conceito clássico do campo de estudos definindo difusão como um processo pelo qual uma inovação é comunicada entre membros de um sistema social através de certos canais no tempo. A partir de alguns exemplos empíricos o autor indicou que, por mais óbvias que sejam as vantagens de determinada inovação, nem sempre elas são amplamente implementadas. Seus estudos demonstraram, por meio da curva S-Shaped, que a distribuição categórica de adotantes de inovações está associada ao fator tempo e a velocidade da adoção. Nesta dinâmica, no início, poucas unidades adotam uma política (os inovadores), em seguida, este grupo influencia os chamados primeiros adotantes, os quais são seguidos depois pelos grupos da primeira e segunda maiorias, momento em que a curva começa a decair. Na ponta da curva encontramse os "atrasados", aqueles que adotaram a inovação muito tempo depois dos primeiros. A distinção entre os grupos é relevante, uma vez que a literatura identifica padrões comportamentais distintos que variam entre um perfil de atores criativos, atores que replicam ideias inovadoras e os grupos mais céticos ou exigentes em termos de avaliação das políticas. Ademais, tais distinções são úteis para testar a validade de teorias que versam sobre o comportamento político do executivo no tempo.

O estudo original de Walker (1969) com foco nos estados americanos explorou em quais condições governos subnacionais copiam políticas uns dos outros. A pergunta central do trabalho é por que governos escolhem determinadas políticas em vez de outras. Uma importante contribuição da pesquisa considera o período inicial e a velocidade com que os estados replicam certas políticas como fatores essenciais ao processo de difusão de inovações. Para o autor, conceitualmente a inovação caracteriza-se como a adoção de um novo programa em uma dada localidade e não como um lançamento de uma ideia original no sistema político.

Outra importante contribuição conceitual foi apresentada por Strang (1991), que definiu a difusão como um fenômeno em que a adoção de uma prática por um governo altera a probabilidade de adoção daquela prática por outros governos. Tal definição é central nos estudos teóricos e empíricos da área. $\mathrm{O}$ autor identifica a utilidade das vertentes teóricas de difusão para entender o processo de descolonização de colônias inglesas e francesas no século XX, incluindo em sua análise tanto variáveis associadas às características internas quanto externas dos países. Os determinantes internos são características políticas, econômicas e sociais de 
uma dada jurisdição. Os determinantes externos são associados à participação formal em redes e à influência regional, como a proximidade geográfica com governos inovadores.

A dicotomia entre ambos os determinantes e a forma de mensurar seus indicadores se tornou um dos grandes debates da literatura de difusão. Por cerca de duas décadas um vasto conjunto de trabalhos testou separadamente o efeito destes fatores. A partir de um estudo inovador, Berry e Berry (1990) unificaram os múltiplos fatores em um construto teórico para analisar os mecanismos causais para o caso da adoção de loterias nos estados norte-americanos. O estudo seminal permitiu explicar o comportamento dos agentes a partir da noção que tanto características locais e externas são ao mesmo tempo importantes para influenciar a tomada de decisão governamental.

Nos anos 2000, novas contribuições teórico-conceituais complexificaram a análise da formação da agenda governamental em regimes democráticos. Elkins e Simmons (2005) em um importante trabalho teórico definiram a difusão como um processo interdependente e não coordenado. O termo "interdependência" é utilizado para designar a influência que decisões já tomadas em algumas jurisdições têm em outras unidades. Já a não coordenação diz respeito à inexistência de uma agência capaz de induzir as tomadas de decisões de outros governos. Em outras palavras, políticas adotadas por um grupo de governos não necessariamente são guiadas por uma ação coordenada pelo Estado ou por uma agência, dado que a interdependência entre as unidades por si só influencia a difusão da política. Esta acepção é importante porque confronta a visão tradicional que considera os casos de adoções múltiplas de políticas como o resultado de um processo coordenado. Em síntese, na perspectiva dos autores, fenômenos de difusão são em geral não uniformes e geram potencialmente um resultado no sistema político. Tal resultado pode ser entendido como a dispersão de um novo modelo de atenção à saúde no território nacional ou a concentração de programas sociais em certas regiões, de modo que o comportamento político dos atores alterou a distribuição da política. Outras transformações no estado da arte das teorias de difusão passam a ocorrer quando modelos de análise de políticas públicas deslocam seu foco analítico dos fatores internos e externos para o estudo de novos mecanismos influenciadores da formação de múltiplas agendas. A percepção de que as ideias assumem valores e especificam relações causais entre os atores em substituição às explicações centradas na escolha racional é classificada por John (1999) como uma vertente pós-positivista. Dessa forma, modelos como coalizões de defesa, múltiplos fluxos e equilíbrio pontuado formaram a base analítica para uma revisita ao policy process que passa a ser visto como um sistema em que ideias e interesses são conciliáveis. Estes modelos serviram de inspiração aos pesquisadores de difusão por justamente demonstrarem que em momentos críticos certas crenças sobre políticas são compartilhadas e prevalecem sobre outros atores. Denota-se, portanto, que as crenças podem asumir um efeito contágio e ser replicadas em redes a partir do papel de empreendedores políticos e comunidades epistêmicas. Como exemplo emblemático da nova literatura, destaca-se o estudo de Howlett, Ramesh e Saguin (2018) sobre como os instrumentos de defesa dos programas de transferência de renda foram compartilhados e defendidos entre burocratas de vários países da América Latina e replicados em outros continentes. Destaca-se ainda como expoente de novas abordagens as análises de natureza institucional (Abrucio et al., 2016) e constitucional (Couto et al., 2018) entre os governos estaduais no Brasil, onde elementos como formas de advocacy, aprendizado e isomorfismo coercitivo são fatores explicativos dos processos de difusão.

Um aspecto relevante a considerar nos estudos de difusão são as bases constitucionais das unidades de análise. $\mathrm{O}$ modelo institucional dos países apresenta variação quanto às regras do federalismo e do sistema eleitoral, o que por definição determina as ações do executivo. Nesse sentido a aplicação dos elementos teóricos que a literatura oferece para medir o comportamento do governo central e dos governos subnacionais apresenta algumas limitações empíricas além da necessidade de diálogo com outras teorias. $\mathrm{O}$ modelo federalista, assim, implica em variados graus de autonomia governamental, permitindo ou limitando decisões sobre a implementação de políticas públicas ou legislações em razão do ordenamento infraconstitucional que restringe a ação dos entes federados abaixo da esfera central de governo. Conforme afirma Füglister (2012), a descentralização dos Estados gera incentivos para o surgimento e difusão de inovações. Nessa perspectiva, 
o Brasil é um caso excepcional na literatura comparada, uma vez que, diferente de outros países como os Estados Unidos, México ou Argentina, suas três esferas de governo gozam de autonomia constitucional para lançar e adotar programas sociais.

Com base nessas vertentes analíticas nós desenvolvemos hipóteses para testar a validade das teorias de difusão para o caso dos Organismos de Políticas para Mulheres. O modelo explicativo proposto compreende tanto a abordagem dos mecanismos clássicos de difusão quanto a abordagem dos determinantes internos e externos. A partir, então, destas premissas as hipóteses do estudo foram definidas e encontram-se detalhadas na seção metodológica.

\section{Políticas para mulheres no Brasil}

A SPM-PR foi criada em 2003. Inicialmente vinculada ao Ministério da Justiça, a pasta passou a constituir uma estrutura de gestão composta pela Secretaria de Políticas do Trabalho e Autonomia Econômica das Mulheres (SAE), pela Secretaria de Enfrentamento à Violência contra as Mulheres (SEV) e pela Secretaria de Articulação Institucional e Ações Temáticas (SAIAT) (Brasil, 2013). As principais ações dos órgãos que formam tal estrutura ocorrem por meio da realização das Conferências Nacionais, que deram origem aos Planos Nacionais de Políticas para as Mulheres (PNPM) e de seus respectivos Comitês de Monitoramento; da instalação de instituições federais, estaduais e municipais sob a rubrica dos Organismos, a fim de elaborar, coordenar e executar as políticas para mulheres no país e cumprir os objetivos dos PNPM e, por fim, de políticas públicas específicas e focalizadas para reduzir a desigualdade entre homens e mulheres.

Entre 2004 e 2013 a agenda institucional do setor apresentou considerável avanço. Neste período ocorreram Conferências Nacionais em 2004, 2007 e 2011, seguidas da criação de Planos Nacionais (2004, 2008 e 2013). Nestes eventos foram elaboradas diretrizes e eixos de ação com o objetivo de promover políticas mais efetivas para mulheres. O primeiro PNPM elaborado em dezembro de 2004 teve sua vigência estimada para os anos de 2005 a 2007. Os resultados da I Conferência Nacional de Políticas para as Mulheres (CNPM) em 2004 foram os principais norteadores da construção do documento, bem como as proposições dos Objetivos de Desenvolvimento do Milênio (2000), a Conferência de Beijing (1995) e as Convenções de Belém do Pará (1994) e do Comitê para a Eliminação de Todas as Formas de Violência contra a Mulher (CEDAW/ONU) (1982). A agenda que norteou a construção da política enfatizou a necessidade de estados e municípios criarem instituições de defesa dos direitos das mulheres (I PNPM, 2004). Além de representantes da esfera federal, estiveram presentes na I CNPM, que deu origem ao PNPM, funcionários estaduais e municipais. Ainda nesse sentido, plenárias municipais e estaduais e Conferências Estaduais antecederam a Conferência.

Enquanto o primeiro PNPM (2004) tinha como principais objetivos a educação inclusiva e não sexista, a saúde das mulheres, os direitos sexuais e reprodutivos das mulheres, o enfrentamento à violência e a gestão de monitoramento da execução de ações para perseguir tais objetivos, o segundo PNPM (2008) passou a incluir temas como o acesso das mulheres aos espaços de poder e decisão, combate ao racismo, sexismo e lesbofobia e a promoção de cultura não estereotipada sobre o papel das mulheres na sociedade (Brasil, 2014). Segundo a SPM, as políticas públicas voltadas para a igualdade de gênero devem ser transversais, isto é, devem ser interligadas nas três esferas federativas (estados, municípios e União) e também entre ministérios, secretarias e demais órgãos responsáveis, pressupondo uma atuação horizontal e não hierárquica.

Do ponto de vista da participação de atores representativos da nova agenda social, destaca-se o espaço do Fórum Nacional de Organismos Governamentais de Políticas para as Mulheres. Contudo, para além da importância do estabelecimento da agenda política para a organização dos debates e proposição de instrumentos administrativos, novas instituições passaram a definir as estratégias de governança e financiamento de programas. Fraser (2003) apud Fórum Nacional de Organismos Governamentais de Políticas para as Mulheres (2014) assinala que a criação de instituições próprias para reduzir as desigualdades 
de gênero implica em estruturas administrativas capazes de receber recursos e melhor conduzir políticas voltadas para a área. Nesse sentido, o Fórum se configura como um locus central que oportunizou por meio do papel das ideias [ ${ }^{\mathrm{ii}}$ ] a criação dos Organismos de Políticas para Mulheres. De acordo com o Fórum, criado pela Portaria n 20, de 11 de junho de 2007, os Organismos "têm a função de fomentar e coordenar a elaboração de políticas públicas e acompanhar a sua implantação nos respectivos locais onde funcionam e ainda ser um polo responsável pela efetividade e defesa dos interesses das mulheres nos níveis estadual/local”. Visando a expansão da agenda e das políticas, a SPM estabeleceu a meta de criação de 1000 Organismos de Políticas para Mulheres até 2015, oficializada por sua inserção no Plano Plurianual 2012-2015.

Fica, assim, evidenciado que a agenda pública apresentou significativo avanço em termos de proposições institucionais dirigidas ao papel da mulher na sociedade e aos seus direitos individuais e políticos. Observase que tal agenda gerou outputs no sistema político que resultaram em novas legislações e programas. $\mathrm{O}$ surgimento do OPM configura-se em um destes resultados. Assim, veremos a seguir como os procedimentos metodológicos foram definidos para se analisar a difusão dos Organismos no Brasil.

\section{Desenho da Pesquisa e Análise dos dados}

Conforme anteriormente exposto, o objetivo geral do estudo é investigar que fatores explicam o comportamento de atores governamentais e suas preferências no tocante à adoção de políticas públicas para mulheres. O aporte metodológico da pesquisa faz uso de dados qualitativos e quantitativos ${ }^{[i i i]}$. Os dados qualitativos, além da revisão bibliográfica da literatura de difusão, foram abordados por meio do mapeamento dos eventos da formação da agenda da política, como fóruns e relatórios de gestão. Os dados quantitativos foram utilizados a partir da organização de um banco de dados original que contabilizou o número de casos de adoção municipal dos Organismos e as características políticas, institucionais, econômicas e sociais e aspectos estruturais como a localização geográfica. $\mathrm{O}$ modelo explicativo da investigação foi estruturado com base em hipóteses relacionadas aos elementos teóricos da literatura de difusão, bem como a fatores pertinentes ao caso analisado. A hipótese 1 considera determinante para a adoção do OPM o fato de o executivo ser gerido por uma prefeita. A hipótese 2 assume a importância da ideologia como um fator que impulsiona a difusão do OPM num cenário onde partidos de esquerda são mais propensos a adotar a política. A hipótese 3 mensura o potencial efeito da competição política pressupondo que o OPM é mais adotado em ambientes políticos eleitoralmente competitivos. As hipóteses 4 e 5 são relativas à influência da capital e do governo estadual em uma situação onde a adoção prévia da política por essas duas unidades influencia positivamente os demais municípios a adotarem os Organismos. Por fim, a hipótese 6 testa se a SPM-PR induziu o processo de adoção da política. Para verificar a correlação entre a variável dependente e as variáveis independentes foram utilizadas estatísticas descritivas e testes de significância para proporções. O modelo tem a seguinte definição:

a) variável dependente: Adoção municipal do OPM.

variáveis independentes: Município administrado por prefeita, ideologia, competição política, município localizado em estado onde a capital adotou o OPM, município localizado em estado que adotou o OPM e papel da SPM-PR.

Tendo em vista que as primeiras adoções de OPM foram em 1998 e as últimas consideradas foram em 2014, até o momento foram 15 anos de implementação da política. Porém, é possível notar muito claramente que a partir de 2003, com a criação da SPM-PR, o número de adoções cresceu consideravelmente. Dos 720 Organismos implementados no Brasil, 695 foram no âmbito municipal e 25 na esfera estadual. Dos 25 OPM estaduais, 12 são secretarias, sete são coordenadorias, duas subsecretarias, uma diretoria, um núcleo, uma gerência e uma superintendência. Vale ressaltar que os estados do Paraná e de Roraima, até 2014, não possuíam OPM estadual $^{[\mathrm{iv}]}$. Ademais, o OPM do Distrito Federal foi considerado estadual e não municipal. 
A distribuição dos OPM por região pode ser verificada na Figura 1.

- Organismos de Políticas para as Mulheres

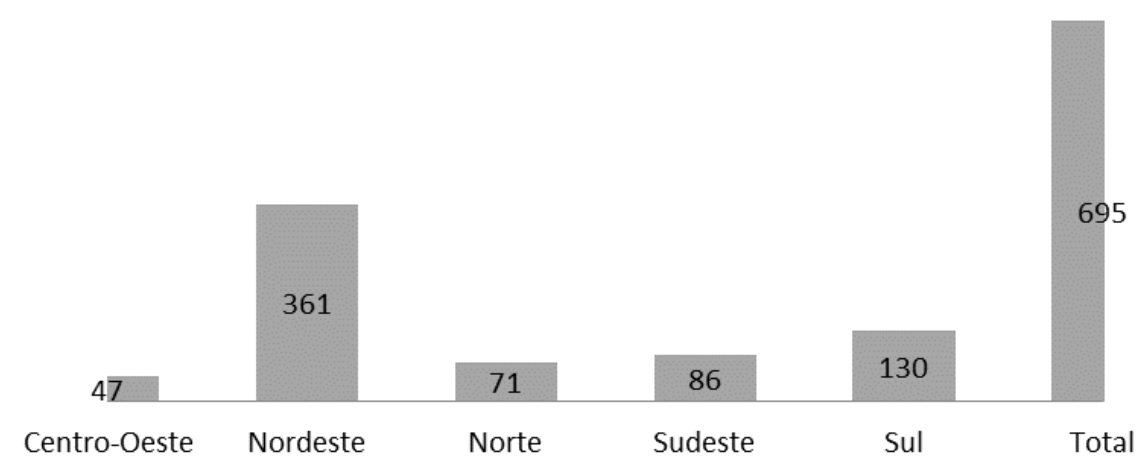

Figura 1. Distribuição regional dos OPM no Brasil de 1998 a 2014

Fonte: Brasil, Presidência da República, Secretaria de Políticas para as Mulheres (2014).

Conforme ilustrado, cerca de 50\% encontram-se na região Nordeste. Porém, quando desagregados os dados por unidade federativa (UF), verifica-se que certos estados predominam na incidência de OPM por região. Na região Centro-Oeste observa-se que Mato Grosso (8\%) tem uma parcela de OPM muito menor em relação ao Mato Grosso do Sul e Goiás, que possuem, respectivamente, 50\% e 42\% dos Organismos da região. Ademais, 43\% dos OPM da região Nordeste se localiza em Pernambuco, desconstruindo a ideia de que o Nordeste aderiu à política unitariamente. Em relação à região Norte, a adoção também é não uniforme: Rondônia e Roraima detêm baixos indicadores em contraste com o Acre. Já na região Sudeste, o estado de São Paulo possui $47 \%$ das adoções, enquanto o Rio de Janeiro e Minas Gerais correspondem a 33\% e 17\%, respectivamente. O Espírito Santo, por outro lado, representou somente 3\% dos OPM criados na região. Por fim, é possível observar que o Rio Grande do Sul obteve $84 \%$ das adoções da região, revelando seu protagonismo na região Sul. É importante, também, que se estabeleça a porcentagem de municípios com OPM por unidade federativa, com base no número de municípios que cada uma possui. De acordo com a Tabela 1, nota-se que o Acre (AC) apresenta 100\% de adoções, o Amapá (AP), 94\%, e Pernambuco (PE), $85 \%$. Com exceção desses três estados, todos os demais tiveram taxa de adoção menor que $50 \%$. Segundo a Secretaria de Articulação Institucional e Ações Temáticas (SAIAT) da SPM-PR, o maior número de OPM nesses locais ocorreu, principalmente, em razão do perfil das secretárias ou coordenadoras dos OPM estaduais (Fontes, 2015). O fato de serem do movimento feminista e o entendimento do seu papel acerca da estrutura política foram determinantes para que esses estados, com o apoio de seus governadores, obtivessem uma taxa de adoção superior a $80 \%$. 
Tabela 1. Taxa de adesão de OPM por Unidade Federativa (UF) de 1998 a 2014

\begin{tabular}{llll}
\multicolumn{5}{c}{ Tabela 1. Taxa de adesão de OPM por Unidade Federativa (UF) de 1998 a 2014} \\
UF & Número de municipios & Número de municipios & Porcentagem de municipios \\
AC & Com OPM & por UF & com OPM por UF \\
AP & 22 & 22 & $100 \%$ \\
PE & 15 & 16 & $94 \%$ \\
SE & 157 & 185 & $85 \%$ \\
MS & 30 & 75 & $40 \%$ \\
RJ & 24 & 79 & $30 \%$ \\
MA & 28 & 92 & $30 \%$ \\
RS & 62 & 217 & $29 \%$ \\
AL & 109 & 497 & $22 \%$ \\
AM & 21 & 102 & $21 \%$ \\
PB & 11 & 62 & $18 \%$ \\
PA & 33 & 223 & $15 \%$ \\
BA & 15 & 144 & $10 \%$ \\
GO & 39 & 417 & $9 \%$ \\
RR & 20 & 246 & $8 \%$ \\
SP & 1 & 15 & $7 \%$ \\
CE & 40 & 645 & $6 \%$ \\
ES & 9 & 184 & $5 \%$ \\
PR & 3 & 78 & $4 \%$ \\
RN & 14 & 399 & $4 \%$ \\
RO & 7 & 167 & $4 \%$ \\
TO & 2 & 52 & $4 \%$ \\
MG & 5 & 139 & $2 \%$ \\
MT & 15 & 853 & $2 \%$ \\
SC & 3 & 141 & $1 \%$ \\
PI & 7 & 295 & $13 \%$ \\
TOtal & 3 & 224 &
\end{tabular}

Fontes: Brasil, Presidência da República, Secretaria de Políticas para as Mulheres (2014); IBGE, Cidades (2014).

A partir do recorte de pesquisa proposto testamos a seguir as variáveis da pesquisa.

As hipóteses 1 e 2 foram desenvolvidas com base em testes de significância para proporções. A base de dados da pesquisa permitiu saber o sexo da liderança política e o partido vencedor da eleição no ano da adoção da política em 454 municípios. Para testar a hipótese 2, usamos a metodologia empregada por Power e Zucco (2008). Os autores elaboraram um espectro ideológico com base em surveys realizados com parlamentares do Congresso Nacional nos anos 1990 e 2005. Tal escala é compreendida entre 0 (extrema esquerda) e 10 (extrema direita).

Hipótese 1: Municípios com prefeitas são mais prováveis de adotarem o OPM.

Hipótese 2: Quanto maior a proporção de municípios administrados por partidos de esquerda e centroesquerda, maior o número de adoções do OPM.

O teste de duas amostras para proporções foi escolhido porque não se tem um censo com o ano de criação da política nos 695 municípios que hoje têm OPM. Caso esse teste não fosse feito, não seria possível testar com precisão se a variável sexo da liderança política foi um dos fatores determinantes na adoção de OPM. De acordo com Stevenson (1981, p. 282) "pequenas diferenças implicam apenas variação casual devido à amostragem (aceitação de $\mathrm{H} 0$ ), enquanto que grandes diferenças implicam precisamente o contrário (rejeição de $\mathrm{H} 0$ )".

Os testes foram bilaterais, já que a porcentagem no contexto de adoção dos OPM poderia ser maior ou menor do que a realidade nacional. Procedendo-se a estatística teste, temos que: 


$$
z=\frac{\left(\frac{x 1}{n 1}\right)-\left(\frac{x 2}{n 2}\right)}{\sqrt{p(1-p)\left[\left(\frac{1}{n 1}\right)+\left(\frac{1}{n 2}\right)\right]}}
$$

Para a Hipótese 2, temos que:

$\mathrm{x} 1=$ total nacional de municípios com prefeitas mulheres;

$\mathrm{x} 2$ = total de prefeituras com OPM gerido por prefeitas mulheres;

n1 = total de municípios no Brasil;

$\mathrm{n} 2$ = total de municípios que adotaram OPM.

Para a Hipótese 3, temos que:

$\mathrm{x} 1=$ total nacional de municípios do partido;

$\mathrm{x} 2$ = total de prefeituras com OPM do partido;

$\mathrm{n} 1=$ total de municípios no Brasil;

$\mathrm{n} 2$ = total de municípios que adotaram OPM.

O teste foi realizado com base em 95\% de significância estatística, o que significa que quando z está compreendido entre $+/-1,96$, não há diferença significativa entre as duas proporções e, nesse caso, se aceita H0. Uma vez contabilizadas estas informações e a fim de testar a hipótese 1, analisou-se se a proporção entre o número de prefeitas que adotaram a política em relação ao total de adoções da política foi diferente da proporção de prefeitas no Brasil em relação ao número total de prefeituras no país. Já conforme a hipótese 3 verificou-se se a proporção do número de prefeituras dos quatro partidos que mais adotaram o OPM (respectivamente PT, PSB, PMDB e PSDB) foi diferente da proporção das prefeituras que esses partidos possuíam nacionalmente. Vale ressaltar que os testes foram feitos, para cada um desses quatro partidos, em cada um dos cinco mandatos municipais que abrangem o período da pesquisa. Este procedimento serviu para verificar se a ideologia importou no processo de difusão da política analisada. A ideia é analisar se o espectro ideológico em que se localiza cada partido influenciou em sua maior criação de OPM.

Em relação à hipótese 1, como é possível observar na Tabela 2, dos 454 municípios com o ano de criação dos OPM disponíveis, 52 (11,5\%) eram administrados por prefeitas mulheres no ano de implementação da política.

Tabela 2. Sexo das lideranças políticas (Executivo) que adotaram OPM

Tabela 2. Sexo das lideranças políticas (Executivo) que
adotaram OPM
\begin{tabular}{l|l|l}
\hline Sexo & Frequência & Porcentagem \\
\hline Homens & 402 & 88,5 \\
\hline Mulheres & 52 & 11,5 \\
\hline Total & 454 & 100 \\
\hline
\end{tabular}

Fontes: Brasil, Presidência da República, Secretaria de Políticas para as Mulheres (2014); Brasil, Tribunal Superior Eleitoral, Eleições anteriores. Elaboração dos autores.

No intuito de descrever se o sexo da liderança iria influenciar na probabilidade de adoção dos OPM, foram feitos testes de diferença entre duas proporções para os cinco períodos de legislatura que vigoraram desde a primeira adoção em 1998 até o ano de 2014. As proporções comparadas foram o número de prefeitas em cada período na esfera nacional e o número de prefeitas que adotaram OPM nos cinco referidos conjuntos de anos.

De 1997 a 2000, 302 prefeituras brasileiras eram geridas por mulheres (5\%), sendo que nenhuma delas adotou OPM. Já em relação ao mandato municipal que se iniciou em 2001 e terminou em 2004, das 317 prefeituras com prefeitas mulheres (6\%), apenas uma criou OPM em seu município, representando $7 \%$ do 
número total de municípios que criaram OPM no período. Em seguida, de 2005 a 2008, das 407 prefeituras geridas por mulheres (7\%), 13 adotaram OPM, representando aproximadamente $10 \%$ das adoções de OPM. Já de 2009 a 2012, o número de prefeituras com prefeitas mulheres passou a ser 506 (9\%), enquanto 27 destas adotaram OPM, o que diz respeito a 12\% das adoções. Por fim, em 2013 e 2014, 657 mulheres ganharam as eleições municipais para a prefeitura (12\%) e 11 destas criaram OPM em suas localidades, o que significa aproximadamente $13 \%$ da implementação. A partir dos testes entre duas proporções temos que z foi igual a 0,417 no período de 1997 a 2000, -0,232 no período de 2001 a 2004, -1,243 no período de 2005 a 2008, $-1,494$ no período de 2009 a 2012 e - 0,282 no período de 2013 a 2014. Os resultados indicam que não houve diferença significativa entre as duas proporções em nenhum dos períodos analisados, já que para haver tal diferença era preciso que $\mathrm{z}$ não estivesse compreendido entre $+/-1,96$.

Prosseguindo para o teste da hipótese 2, conforme indica a Tabela 3, os prefeitos que mais adotaram OPM nos municípios brasileiros foram os pertecentes aos partidos PT (19\%), PSB (17\%), PMDB (13\%) e PSDB (9\%). No total, 19 partidos aderiram à política. Com vistas a entender se o fato de o PT, PSB, PMDB e PSDB terem adotado mais OPM indica maior propensão desses partidos à adesão da política, outro teste de diferença entre duas proporções foi realizado. Para cada um desses quatro partidos, nos cinco períodos analisados (1997-2000, 2001-2004, 2005-2008, 2009-2012 e 2013-2014), comparou-se se a porcentagem de incidência do partido nacionalmente era equivalente à porcentagem de suas prefeituras com OPM.

Tabela 3. Partido do(a) Prefeito(a) que adotou o OPM Municipal (1997-2014)

\begin{tabular}{|c|c|c|}
\hline $\begin{array}{l}\text { Partido dos } \\
\text { prefeitos que } \\
\text { adotaramo } \\
\text { OPM }\end{array}$ & $\begin{array}{l}\text { Número de } \\
\text { municípios } \\
\text { por partido }\end{array}$ & $\begin{array}{l}\text { Porcentagem de } \\
\text { incidência do } \\
\text { partido } \\
\text { nacionalmente } \\
\text { entre municipios } \\
\text { com opM }\end{array}$ \\
\hline PT & 84 & $19 \%$ \\
\hline PSB & 75 & $17 \%$ \\
\hline PMDB & 58 & $13 \%$ \\
\hline PSDB & 43 & $9 \%$ \\
\hline PDT & 33 & $7 \%$ \\
\hline PTB & 32 & $7 \%$ \\
\hline DEM/PFL & 23 & $7 \%$ \\
\hline PR & 23 & $5 \%$ \\
\hline PP & 20 & $4 \%$ \\
\hline PPS & 9 & $2 \%$ \\
\hline PSD & 9 & $2 \%$ \\
\hline PCdoB & 8 & $2 \%$ \\
\hline PV & 8 & $2 \%$ \\
\hline PRB & 6 & $1 \%$ \\
\hline PL & 4 & $1 \%$ \\
\hline PSC & 4 & $1 \%$ \\
\hline PTdoB & 4 & $1 \%$ \\
\hline PMN & 2 & $0 \%$ \\
\hline Total & 454 & $100 \%$ \\
\hline
\end{tabular}

Fontes: Brasil, Presidência da República, Secretaria de Políticas para as Mulheres

(2014); Brasil, Tribunal Superior Eleitoral, Eleições anteriores. Elaboração dos autores.

O resultado foi que, de 1997 a 2000, a proporção de prefeituras do PT e do PSB com OPM foi maior que a proporção de prefeituras do PT e do PSB nacionalmente. PMDB e PSDB não tiveram diferenças significativas entre as duas proporções. Afinal, para o PT, no período citado, z foi igual a $-3,498$ e para o PSB $\mathrm{z}$ foi igual a $-2,990$. Como o $\mathrm{z}$ foi menor do que $-1,96$, houve diferença significativa entre as duas proporções. Já para o PMDB e PSDB z foi igual a, respectivamente, 1,062 e 0,849. 
Em relação aos períodos que compreendem 2001 a 2004 e 2005 a 2008, o resultado foi que a proporção de prefeituras do PT com OPM foi maior que a proporção de prefeituras do PT nacionalmente, já que o valor de z para o PT de 2001 a 2004 foi $-8,069$ e de 2005 a 2008 resultou em -8,361. PSB, PMDB e PSDB não tiveram diferenças significativas entre as duas proporções. De 2001 a 2004 e de 2005 a 2008 o z relacionado ao PSB foi igual a, respectivamente, $-1,158$ e -1,002. De 2001 a 2004 e de 2005 a 2008 o z relacionado ao PMDB foi igual a, respectivamente, 1,382 e 1,160. Por fim, de 2001 a 2004 e de 2005 a 2008 o z relacionado ao PSDB foi igual a, respectivamente, $-1,052$ e 1,420.

Já de 2009 a 2012, a configuração se modifica. Enquanto PT e PSDB não obtiveram diferenças significativas entre as duas proporções (z para PT foi -1,204 e para PSDB, 1,485), a proporção de prefeituras do PSB com OPM foi maior que a proporção de prefeituras do PSB nacionalmente (z para PSB foi igual a -9,907). Isso ocorreu por conta da criação de OPM em 110 municípios pernambucanos, muitos deles governados pelo PSB. O PMDB, no entanto, teve a proporção com OPM menor que a proporção de suas prefeituras nacionalmente, como é possível verificar com o $\mathrm{z}$ igual a 3,758 .

Em 2013 e 2014, mais uma vez, a proporção de prefeituras do PSB com OPM foi maior que a proporção de suas prefeituras em todo o Brasil, uma vez que $\mathrm{z}$ foi igual a $-4,404$. Enquanto isso, a proporção de prefeituras do PSDB com OPM foi menor que a proporção de prefeituras do PSDB nacionalmente, como é possível observar com o z igual a 2,844. Os demais partidos não obtiveram diferença significativa entre proporções (PMDB com z igual a 1,049 e PT com $\mathrm{z}$ igual a -1,388).

A conclusão é que dos cinco períodos analisados, em três deles, o fato de o prefeito ser do PT influenciou na adoção de OPM. O mesmo ocorreu para prefeitos do PSB, que em três dos cinco períodos citados tiveram sua proporção de municípios com OPM maior que a proporção de prefeituras do partido nacionalmente. Nesse sentido, a variável partidária importou para o processo de difusão quando observadas essas duas legendas. No entanto, no caso do PMDB e do PSDB não se verifica uma proporção significativa suficiente para guiar a difusão do OPM. Isso ocorre pelo fato de esses partidos terem administrado um número expressivo de municípios, mas seus gestores optaram por não experimentar a inovação democrática. Tendo em vista que o fato de o prefeito ser do PT ou do PSB importou na adoção de três dos cinco períodos analisados, é possível concluir também que em parte a ideologia representou fator importante para explicar a difusão da política.

Segundo Polsby, quanto mais competitiva a eleição para um cargo, mais o eleito irá inovar politicamente (apud Dolowitz e Marsh, 1996). Estudos recentes de difusão têm medido competição política em termos de margem de vitória percentual do candidato vencedor sobre os demais candidatos ou entre os dois primeiros colocados, considerando a diferença de até $10 \%$ dos votos válidos como indicador de alta competição (Sugiyama, 2008; Coêlho, 2012; Coêlho et al., 2016). O procedimento metodológico para este caso testa comparativamente se municípios com OPM apresentam eleições disputadas, o que configuraria a confirmação da hipótese da pesquisa.

Hipótese 3: Quanto maior a competição política municipal maior a possibilidade de adotar o OPM.

O teste da hipótese foi aplicado para os 454 municípios em que foi possível obter o dado da adoção. Conforme a Tabela 4 pode-se verificar que majoritariamente os municípios em questão tiveram média de margem de vitória eleitoral acima de $10 \%$, o que evidencia que a competição política não importou para a difusão do OPM no período analisado. 
Tabela 4. Competição Política (média percentual - diferença de votos entre os dois primeiros colocados)

$\begin{aligned} & \text { Tabela 4. Competição Política (média percentual - diferença } \\
& \text { de votos entre os dois primeiros colocados) }\end{aligned}$
\begin{tabular}{l|l|l|l}
\hline Estado & $\begin{array}{l}\text { Média margem } \\
\text { de vitória }\end{array}$ & Estado & $\begin{array}{l}\text { Média margem de } \\
\text { vitória }\end{array}$ \\
\hline AP & 6,58 & RJ & 17,33 \\
\hline MT & 7 & TO & 18,25 \\
\hline SC & 9 & CE & 19,14 \\
\hline RO & 11,5 & PB & 20,52 \\
\hline AC & 11,53 & SP & 22,03 \\
\hline RR & 12 & AM & 22,66 \\
\hline PR & 12,5 & MS & 23,31 \\
\hline RS & 13,05 & PI & 23,5 \\
\hline PA & 13,42 & AL & 25,66 \\
\hline MA & 15,48 & MG & 28,75 \\
\hline BA & 15,82 & RN & 31,5 \\
\hline SE & 16,33 & ES & 38,33 \\
\hline PE & 16,79 & GO & 52,4
\end{tabular}

Fontes: Brasil, Presidência da República, Secretaria de Políticas para as Mulheres

(2014); Brasil, Tribunal Superior Eleitoral, Eleições anteriores, Elaboração dos autores.

Segundo a tipologia sugerida por Shipan e Volden (2008), há quatro mecanismos envolvidos no processo de difusão de políticas: Aprendizado, emulação, competição entre cidades próximas e coerção/pressão pelo governo do Estado. No mecanismo de emulação, mais do que as consequências da política e a possibilidade de sua adaptação na jurisdição que irá copiá-la, o que mais importa é seu simbolismo e imagem de sucesso. Nessa perspectiva, é muito comum cidades menores emularem políticas de cidades maiores pelo desejo de se assemelharem às capitais e locais mais desenvolvidos. Por esse motivo, julgou-se adequado analisar a adoção prévia do OPM pelas capitais e estados e sua potencial influência no comportamento político municipal.

Hipótese 4: A adoção prévia da política pelas capitais influencia a adoção nos demais municípios do estado.

Hipótese 5: A adoção prévia da política pelos governos estaduais influencia a adoção nos demais municípios do estado.

A Tabela 5 ilustra, para o período 1998-2014, o ano em que as capitais estaduais adotaram o OPM. A exceção observada é Cuiabá, no Mato Grosso. Para medir esta suposta correlação, verificou-se se as capitais foram pioneiras na adoção de OPM para cada unidade da federação. Em dez estados ( $40 \%$ do total) a situação se confirma. Os dados também revelam que há estados onde embora as capitais não tenham sido pioneiras, estas adotaram o OPM a partir do segundo ano ( $28 \%$ de casos) e do terceiro ano (32\% das observações). A conclusão confirma então a influência da capital sobre o comportamento político dos demais municípios para cada estado. 
Tabela 5. Ano de criação do OPM nas capitais brasileiras (1998-2014)

\begin{tabular}{|c|c|c|c|c|c|}
\hline Estado & Capital & $\begin{array}{l}\text { Ano de } \\
\text { criação } \\
\text { do OPM }\end{array}$ & Estado & Capital & $\begin{array}{l}\text { Ano de } \\
\text { Criação } \\
\text { do OPM }\end{array}$ \\
\hline MG & $\begin{array}{l}\text { Belo } \\
\text { Horizonte }\end{array}$ & 1998 & RR & Boa Vista & 2009 \\
\hline $\mathrm{BA}$ & Salvador & 2004 & RS & $\begin{array}{l}\text { Porto } \\
\text { Alegre }\end{array}$ & 2010 \\
\hline MS & $\begin{array}{l}\text { Campo } \\
\text { Grande }\end{array}$ & 2005 & PA & Belém & 2010 \\
\hline $\mathrm{RO}$ & Porto Velho & 2005 & AL & Maceió & 2011 \\
\hline $\mathrm{AP}$ & Macapá & 2005 & $\mathrm{GO}$ & Goiânia & 2011 \\
\hline $\mathrm{AC}$ & Rio Branco & 2005 & PI & Teresina & 2011 \\
\hline $\mathrm{PB}$ & João Pessoa & 2005 & RN & Natal & 2011 \\
\hline TO & Palmas & 2005 & $\mathrm{SE}$ & Aracaju & 2011 \\
\hline $\mathrm{AM}$ & Manaus & 2006 & RJ & $\begin{array}{l}\text { Rio de } \\
\text { Janeiro }\end{array}$ & 2012 \\
\hline ES & Vitória & 2006 & $\mathrm{PE}$ & Recife & 2013 \\
\hline MA & São Luís & 2006 & PR & Curitiba & 2013 \\
\hline $\mathrm{CE}$ & Fortaleza & 2007 & SP & São Paulo & 2013 \\
\hline $\mathrm{SC}$ & Florianópolis & 2008 & & & \\
\hline
\end{tabular}

Fonte: Brasil, Presidência da República, Secretaria de Políticas para as Mulheres (2014). Elaboração dos autores.

A potencial influência da adoção do OPM pelos governos estaduais sobre os municípios do seu próprio território foi testada com base nos dados da Tabela 6. Observa-se que a maior parte dos Organismos estaduais foi adotada entre os anos de 2007 a 2011. A perspectiva da literatura é que municípios menores tendem a emular as inovações de governos centrais. Segue-se aqui a mesma lógica da hipótese sobre a influência das capitais. Ao contrário da aprendizagem, que foca no ato - como ele foi adotado, se foi efetivo, se teve consequências -, a imitação foca no ator - como outro governo procedeu e como se pode aprender entre pares (Shipan \& Volden, 2008). A análise demonstra que 25\% dos governos estaduais adotaram o OPM antes dos governos locais e que, em 38\% dos casos, as adoções municipais ocorreram no segundo ano após a adoção da política pelo estado. Nesse sentido, a influência do governo estadual sobre os governos municipais se configura num fator importante e que explica o avanço dos Organismos. Um olhar sobre o contexto da formação da agenda dos OPM nos permite inferir que os estados também foram importantes na medida em que contaram com atores chaves do processo. Os casos de alguns estados como Pernambuco, Maranhão, Acre e Rio de Janeiro são emblemáticos. Os estados que, em geral, mais adotaram OPM contaram com secretárias que advinham do movimento feminista e que dispunham de conhecimento sobre a agenda política, bem como histórico de militância na área. Tais fatores reforçam a noção da importância de empreendedoras políticas como agentes sociais relevantes em processo de disseminação de inovações em sistemas políticos tradicionais. 
Tabela 6. Ano de criação do OPM nos governos estaduais (1999-2014)

\begin{tabular}{llll}
\multicolumn{5}{c}{ Tabela 6. Ano de criação do OPM nos governos estaduais (1999-2014) } \\
UF & Data de criação & UF & Data de criação \\
MS & 1999 & MT & 2010 \\
AL & 2004 & AC & 2011 \\
AP & 2005 & BA & 2011 \\
MA & 2006 & DF & 2011 \\
SC & 2006 & ES & 2011 \\
GO & 2007 & MG & 2011 \\
PA & 2007 & RS & 2011 \\
PE & 2007 & TO & 2011 \\
RJ & 2007 & SP & 2012 \\
RN & 2007 & AM & 2013 \\
SE & 2007 & PI & 2013 \\
CE & 2009 & RO & 2014 \\
PB & 2009 & &
\end{tabular}

Fonte: Brasil, Presidência da República, Secretaria de Políticas para as Mulheres (2014). Elaboração dos autores.

De acordo com Welch e Thompson (1980) e Mossberger (1999), governos centrais interessados em descentralizar políticas públicas ofertam uma estrutura de incentivos seletivos para estimular a adoção de novos modelos de políticas. Documentos elaborados pela SPM-PR e os Planos Nacionais de Políticas para as Mulheres foram analisados para testar a hipótese 7 , que sugere o forte papel indutor desse órgão na disseminação do OPM nos municípios brasileiros.

Hipótese 6: A Secretaria de Políticas para as Mulheres federal impulsionou o processo de adoção da política.

É interessante ressaltar que somente sete municípios possuíam OPM anterior a criação da SPMPR, em 2003, representando menos de $2 \%$ dos casos. A partir de 2005, o número de casos aumentou consideravelmente, sendo que em 2009 houve um pico de criações de OPM, com 118 novos organismos criados. Entre 2010 e 2012 o número de adoções decresceu em relação ao período anterior, mas em 2013 ocorreu um novo pico, com mais 64 instituições registradas. A partir de 2005 é possível verificar um crescimento de adoções de OPM nos municípios brasileiros. Eventos idealizados pela SPM-PR, como a realização da $1{ }^{\text {a }}$ CNPM e o debate em torno do PNPM, foram relevantes para a formação e consolidação da agenda $^{[\mathrm{v}]}$. A Figura 2, no formato da curva S-Shaped, informa a evolução das adoções da política no tempo, cumulativamente. 


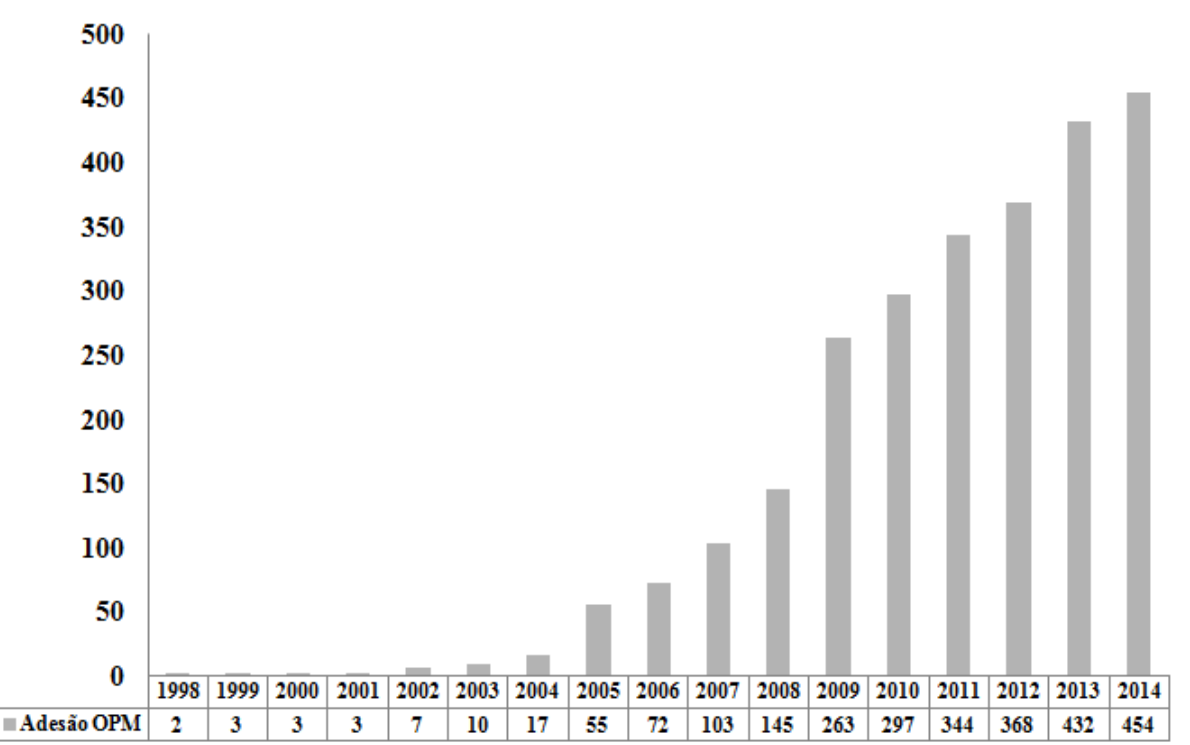

Figura 2. Curva S-Shaped da adoção dos OPM no tempo (1998 a 2014) Fonte: Brasil, Presidência da República, Secretaria de Políticas para as Mulheres (2014). Elaboração dos autores.

Uma das evidências do papel decisivo da SPM-PR é a criação de mecanismos pelos quais os municípios passaram a enviar propostas para a criação dos Organismos. O instrumento é o Sistema de Convênios (SICONV) do governo federal, a partir do qual os projetos aprovados recebem recursos por meio de transferências voluntárias ${ }^{[\mathrm{vi}]}$. A SPM-PR auxilia ainda com recursos financeiros os municípios para a realização de ações voltadas à capacitação dos funcionários e para a compra de equipamentos, por exemplo. Ademais, a desvinculação do Ministério da Justiça resultou em recursos e orçamento próprios para a SPMPR. O orçamento da pasta evoluiu de 2003 a 2014, como demonstrado a partir da figura 3. Em 2003, no que diz respeito à execução orçamentária, é possível observar um aporte da ordem de $\mathrm{R} \$ 3,5$ milhões em valores pagos pela pasta. Já em 2004, o valor pago passa para $\mathrm{R} \$ 14,8$ milhões. Em 2008 ele atinge $\mathrm{R} \$ 37,1$ milhões e descresce para $\mathrm{R} \$ 23,4$ milhões em 2009. Já em 2010 ele volta a crescer, atingindo o valor de $\mathrm{R} \$ 50,9$ milhões, mas diminui novamente em 2011 e 2012, com, respectivamente, $\mathrm{R} \$ 26,4$ e R $\$ 25,9$ milhões. Em seguida, em 2013, ele cresce 79\% em relação a 2012. Por fim, em 2014, ele atinge o valor de $\mathrm{R} \$ 73$ milhões. Em síntese, temos que a constituição de uma Secretaria de Políticas para Mulheres na esfera federal influenciou na adoção de OPM nos municípios brasileiros por conta de quatro fatores principais: Institucionalização da política por meio da organização de eventos (sobretudo as três conferências nacionais), aumento expressivo de seus recursos ao longo dos anos, inserção de metas para o tema nos planos plurianuais e convênios voltados à ação de políticas para mulheres realizados com municípios.

\section{Conchusões}

Este artigo apresentou uma análise acerca dos condicionantes político-institucionais que determinaram a formação e difusão da agenda dos OPM entre os municípios brasileiros. Uma conclusão de caráter geral é que o redesenho da rede de proteção social no país continua dependendo do papel indutor do governo federal, contudo, cada vez mais, decorre do julgamento dos governos locais. Em outras palavras, o estudo demonstra que as políticas públicas no Brasil tendem a se descentralizar em função de aspectos relevantes como a urgência para o atendimento das demandas sociais, mas também está associada à conjuntura do sistema político e suas regras. Em parte, tal quadro é resultante do desenho federativo que permite aos governos locais decidirem se adotam ou não uma nova política de outra esfera governamental. Ademais, a tomada de decisão é afetada pela relação de custos e benefícios de se implementar um novo modelo de prestação de serviço à 
sociedade. Os objetivos do estudo foram explicar qual a resposta do Estado para atender a uma demanda social crescente e como o sistema político adotou a inovação OPM. A análise demonstra que o avanço do modelo deve-se à ação coordenada do governo federal, às características regionais e ao papel das lideranças locais. Tal dinâmica ilustra que o sistema político respondeu positivamente ao novo modelo de solução, dado que as networks foram ativadas e os atores defensores dos instrumentos da política exerceram papel decisivo na consolidação do novo arranjo institucional. Tendo em vista que o objetivo do estudo foi explicar que variáveis mais influenciaram a decisão em adotar o OPM, a análise buscou apoio nas bases conceituais e teóricas da literatura de difusão de políticas. Mais precisamente, a análise procurou mensurar a influência dos determinantes internos e externos e outros fatores intrínsecos ao fenômeno em questão. Para tanto, construímos um desenho de pesquisa com o intuito de definir um modelo explicativo com base no contexto histórico, atributos da política e mapeamento dos eventos de interesse. Concluimos que o arcabouço teórico e a metodologia empregados foram úteis para mensurar o comportamento dos governos frente à decisão de adotar ou não os Organismos. Do ponto de vista das diferenças entre as abordagens tradicionais, como o policy process ou policy analysis e a literatura de difusão, destacamos a importância de testar os atributos dos governos sub-nacionais, uma vez que comprovamos empiricamente que a implementação dos OPM não se configura em um processo de descentralização federal, sendo guiada majoritariamente pelas agendas locais.

No que diz respeito aos determinantes externos, verificou-se que a influência estadual foi maior que a influência regional. Isso por que não houve uma uniformidade nas adoções dos estados em cada região. Pernambuco, por exemplo, com $43 \%$ das adoções da região nordeste, não influenciou o comportamento dos demais estados nordestinos no tocante à adesão da política. $\mathrm{O}$ perfil das secretárias estaduais de políticas para as mulheres foi fator determinante para explicar o sucesso na taxa de criação de OPM. Com o apoio do governo estadual, essas profissionais divulgaram a política em seus estados e ajudaram a implementá-la. Nesse sentido, alguns atores específicos da agenda política foram centrais no processo de disseminação do modelo OPM no país.

Já em relação aos determinantes internos, os resultados assinalam que algumas variáveis não explicam o fenômeno, enquanto outras variáveis confirmam as hipóteses da pesquisa. A competição política revelou que ambientes políticos competitivos não são necessariamente mais propensos a avançar em direção a uma agenda de inovações institucionais. $\mathrm{O}$ determinante interno municipal que mais influenciou o processo de difusão da política foi a variável partidária utilizada para medir ideologia. O PT e o PSB foram os partidos que mais adotaram o OPM, resultado que corrobora com a importância de conteúdos programáticos de esquerda. Quanto aos municípios administradas por prefeitas, constata-se que o sexo da liderança política não foi determinante. Verifica-se, ademais, que a partir da inovação de instâncias centrais como capitais e governos estaduais, parte dos municípios do país deciciu copiar o mesmo tipo de política. No que diz respeito ao papel da SPM-PR, as conclusões apontam que as transferências voluntárias repassadas aos municípios e a agenda de conferências nacionais constituíram benefícios seletivos para que estes adotassem a política.

No âmbito internacional os estudos sobre políticas para mulheres consideram centrais as relações intergovernamentais e o papel da sociedade civil para o processo de formulação e implementação de novos modelos institucionais. Um dos principais recortes temáticos trata justamente do papel dos governos locais no avanço pela igualdade de gênero, revelando a importância de pesquisas como as do OPM no Brasil. HarelShalev (2013) em contribuição recente analisou o impacto que políticas voltadas para autonomia de minorias têm sobre as mulheres muçulmanas na Índia. O estudo de Cook e Cusack (2010) analisou comparativamente entre países a "Convenção sobre a Eliminação de Todas as Formas de Discriminação Contra a Mulher"”. A investigação de Ray (2008) compara as políticas de licença paternidade e maternidade em 21 países da Organização para a Cooperação e Desenvolvimento Econômico (OCDE). Em suma, a agenda de pesquisa reconhece o valor social das políticas, mas, de forma complementar, aponta para a relevância do impacto de novas legislações no sistema político. 


\section{REFERÊNCIAS BIBLIOGRÁFICAS}

ABRUCIO, F. L. ; SANO, H. ; SEGATTO, C. I. Difusão de Políticas Públicas. Cooperação Interestadual: O papel do Consad e do Consed na disseminação de reformas e políticas públicas. In: Carlos Aurélio Pimenta de Farias; Denilson Bandeira Coêlho; Sidney Jard da Silva (Org.). Difusão de Políticas Públicas. 1a ed. São Bernardo do Campo: EdUFABC, 2016, v. , pp. 103-132.

\section{BATISTA, Mariana.}

A difusão da Lei de Acesso à Informação nos municípios brasileiros: fatores internos e externos. Brasília: Enap, 2017.

BERRY, Frances Stoke; BERRY, William D. State lottery: adoptions as policy innovations: an event history analysis. American Political Science Review, v. 84, n. 2, pp. 395-415, 1990.

BERRY, Frances Stoke; BERRY, William D. Tax innovation in the states: capitalizing on political opportunity. American Journal of Political Science, v.36, n.3, p.715-742, 1992.

BOUSHEY, G. (2016). Targeted for Diffusion? How the Use and Acceptance of Stereotypes Shape the Diffusion of Criminal Justice Policy Innovations in the American States. American Political Science Review, 110(1), pp. 198-214.

BRASIL. Presidência da República, 2016. Lei No 10.683, de 28 de maio de 2003. Disponível em: http:// www.planalto.gov.br/ccivil_03/LEIS/2003/L10.683.htm. Acesso em 10 abr. 2016.

BRASIL. Presidência da República. Secretaria de Políticas para as Mulheres. Organograma. [Brasília, 2013]. Disponível: http://www.spm.gov.br/sobre/a-secretaria/organograma-spm-decreto-8-030-2013. Acesso em 5 fev. 2015.

BRASIL. Presidência da República. Secretaria de Políticas para as Mulheres. Publicações/Documentações. [Brasília], 2014. Disponível em: http://www.spm.gov.br/assuntos/organismos-governamentais-df-estados-e-municipios/ publicacoes-documentacoes. Acesso em 4 abr. 2015.

BRASIL. Câmara dos Deputados. Orçamento Brasil, 2016. Disponível em: http://www2.camara.leg.br/atividadelegislativa/orcamentobrasil/loa/loa2002. Acesso em 03 mai. 2016.

BRASIL. Tribunal Superior Eleitoral. Eleições anteriores. Disponível: www.tse.jus.br. Acesso em 10 mar. 2015.

BROOKS, S. M. (2015). Social Protection for the Poorest: The Adoption of Antipoverty Cash Transfer Programs in the Global South*. Politics \& Society, 43(4), pp. 551-582.

COOK, R.; CUSACK S. Gender Stereotyping: Transnational Legal Perspectives. Philadelphia: University of Pennsylvania Press, 2010.

COÊLHO, Denilson B., Political competition and the diffusion of Conditional Cash Transfers in Brazil.Brazilian Political Science Review. São Paulo, v. 6, n. 2, pp. 56-87, 2012.

COÊLHO, Denilson B.; CAVALCANTE, Pedro; TURGEON, Mathieu. Mecanismos de difusão de políticas sociais no Brasil: uma análise do Programa Saúde da Família. Revista Brasileira de Sociologia e Política, vol. 24, n. 58, jun-2016.

COÊLHO, Denilson B. Mecanismos Políticos e Institucionais da Difusão de Políticas. In: Faria, Carlos Aurélio Pimenta; Coêlho, Denilson Bandeira \& Silva, Sidney Jard. (eds.):: Difusão de Políticas Públicas. Editora da UFABC, 2016.

COLLIER, David; MESSICK, Richard E. Prerequisites versus diffusion: testing alternative explanations of social security adoption. The American Political Science Review, v. 69, n. 4, pp. 1299-1315, 1975.

COUTO, Cláudio Gonçalves; ABSHER-BELLON, Gabriel Luan. Imitação ou coerção? Constituições estaduais e centralização federativa no Brasil. Rev. Adm. Pública, Rio de Janeiro, v. 52, n. 2, pp. 321-344, Apr. 2018.

DOLOWITZ, David; MARSH, David. Who learns what from whom: a review of the policy transfer literature. Political Studies, XLIV, pp. 343-357, 1996.

ELKINS, Zachary; SIMMONS, Beth. On waves, clusters, and diffusion: conceptual framework. Annals of the American Academy of Political Science and Sociological Science, v. 598, n. 1, pp. 33-51, 2005. 
FARIA, Carlos Aurélio Pimenta. A difusão de políticas sociais como estratégia de inserção internacional: Brasil e Venezuela comparados. Interseções, Rio de Janeiro, v. 14, n. 2, pp. 335-371, 2012.

FARIA, Carlos Aurélio Pimenta. Ideias, conhecimento e políticas públicas: um inventário sucinto das principais vertentes analíticas recentes. Revista Brasileira de Ciências Sociais, v. 18, n. 51, pp. 21-30, 2003.

FONTES, Ângela. Informações sobre OPM. Brasília: SPM-PR, 2015. (Comunicação oral).

FÓRUM NACIONAL DE ORGANISMOS GOVERNAMENTAIS DE POLÍTICAS PARA AS MULHERES, 2014. Protagonismo dos OPM na execução das políticas para mulheres: encontros regionais. [Brasília], 2014. Disponível em: https://www.spm.gov.br/assuntos/organismos-governamentais-df-estados-emunicipios/publicacoes-documentacoes/protagonismo/textos-para-discussao.pdf. Acesso em 24 nov. 2014.

FÜGLISTER, Katharina. Where does learning takes place? The role of intergovernmental cooperation in policy diffusion. European Journal of Political Research, v. 51, pp. 316-349, 2012.

GILARDI, Fabrizio. 2012. “Transnational Diffusion: Norms, Ideas, and Policies.” InWalter Carlsnaes, Thomas Risse, and Beth Simmons (eds), Handbook of International Relations, 2nd edition, SAGE Publications, pp. 453-477.

GONNET, Cecilia Osorio. Mecanismos de difusión de los Programas de Transferencia Condicionada en América Latina: El caso chileno. Íconos. Revista de Ciencias Sociales. Num. 53, Quito, septiembre 2015, pp. 31-48.

GRAHAM, Erin; SHIPAN, Charles; VOLDEN, Craig. The diffusion of policy diffusion research in political science. British Journal of Political Science, v. 43, n. 3, 2008.

HAREL-SHALEV A, 2013. Policy Analysis beyond Personal Law: Muslim Women's Rights in India. Politics \& Policy. V. 41, I. 3, pp. 384-419.

HOWLETT, Michael; RAMESH, M; SAGUIN, Kidjie. Difusão dos PTCs da América Latina para a Ásia: o caso do programa 4Ps nas Filipinas. Rev. Adm. Pública, Rio de Janeiro , v. 52, n. 2, pp. 264-284, Apr. 2018.

IBGE. Cidades, 2014. Disponível em: http://www.cidades.ibge.gov.br/xtras/home.php. Acesso em 24 fev. 2015.

IPEA. PNAD 2009: primeiras análises: o mercado de trabalho brasileiro em 2009. [Brasília], 2010. 14p. (Comunicado do IPEA, n.62). Disponível em: http://www.ipea.gov.br/portal/images/stories/PDFs/ comunicado/100923_comunicadoipea62.pdf.. Acesso em 9 jun. 2015.

IPSA. The Role of Local Government in Advancing Gender Equality. 24th World Congress of Political Science.Disponível em: https://istanbul2016.ipsa.org/my-ipsa/events/istanbul2016/panel/role-localgovernment-advancing-gender-equality. Acesso em 23 nov. 2015.

JOHN, Peter. (1999), Analysing public policy. Londres, Pinter.

MAGGETTI, Martino \& GILARDI, Fabrizio (2014). Network governance and the domestic adoption of soft rules, Journal of European Public Policy, 21:9, pp. 1293-1310.

MINTROM, Michael. The state-local nexus in policy innovation diffusion: the case of School Choice. Publius: The Journal of Federalism, v. 27, n. 3, pp. 41-59, 1997.

MOSSBERGER, Karen. "State-federal diffusion and policy learning”. Publius, vol. 29, no3, pp. 31-50. 1999.

OLIVEIRA, Osmany Porto, Embaixadores da participação: a difusão internacional do Orçamento Participativo a partir do Brasil. 2013. 291f. Tese (Doutorado em Ciência Política) - Departamento de Ciência Política da Faculdade de Filosofia, Letras e Ciências Humanas, Universidade de São Paulo, 2013. Disponível: http:// www.usjt.br/arq.urb/arquivos/abntnbr6023.pdf. Acesso em 6 jun. 2015.

PACHECO, J. (2012). The Social Contagion Model: Exploring the Role of Public Opinion on the Diffusion of Antismoking Legislation across the American States. The Journal of Politics, 74(1), pp. 187-202.

PEREIRA, Alexsandro Eugenio et al. A governança facilitada no Mercosul: transferência de políticas e integração nas áreas de educação, migração e saúde. Rev. Adm. Pública, Rio de Janeiro , v. 52, n. 2, pp. 285-302, Apr. 2018.

PETERS, B. Guy. Policy transfer between governments: the case of administrative reforms. West European Politics, v. 20, n. 4, pp. 71-88, 1997.

RAY R., 2008. A Detailed Look at Parental Leave Policies in 21 OECD Countries. Center for Economic and Policy Research. Disponível: http://www.cepr.net/publications/reports/plp>. Acesso em novembro de 2015.

ROGERS, Everett M. Diffusion of innovations. 5. ed. New York: Free Press, 1995. 
SHIPAN, Charles R.; VOLDEN, Craig.Bottom-up federalism: the diffusion of antismoking policies from U.S. cities to states. American Journal of Political Science, v. 50, n. 4, pp. 825-843, 2006.

SHIPAN, Charles R.; VOLDEN, Craig.The mechanisms of policy diffusion. American Journal of Political Science, v. 52, n. 4, pp. 840-857, Oct. 2008.

SHIPAN, Charles R., \& VOLDEN, Craig. Policy Diff usion: Seven Lessons for Scholars and Practitioners: Theory to Practice. Public Administration Review, 2012.

SPADA, Paolo. The economic and political effects of participatory budgeting. Disponível: http:// www.researchgate.net/ publication/241756926_The_Economic_and_Political_Effects_of_Participatory_Budgeting. Acesso em: 6 jun. 2015. Preparado para apresentação no Congress of Latin American Studies Association, Rio de Janeiro, Brasil, 11-14 de Junho, 2009.

STEVENSON, William J. Estatística aplicada à administração. São Paulo: Harper \& Row do Brasil, 1981.

STRANG, David. Adding social structure to diffusion models: an event history framework. Sociological Methods and Research, v. 19, n. 3, pp. 324-53, 1991.

SUGIYAMA, Natasha B., Theories of policy diffusion: social sector reform in Brazil. Comparative Political Studies, v. 41, n. 2, pp. 193-216, 2008.

WALKER, Jack L. The diffusion of innovations among the American states. American Political Science Review, v. 63, n. 3, pp. 880-899, 1969.

WAMPLER, Brian. A difusão do orçamento participativo brasileiro: boas práticas devem ser promovidas? OpiniãoPública, Campinas, v. 14, n. 1, pp. 65-95, jun. 2008.

WELCH, Susan and THOMPSON, Kay. "The impact of federal incentives on state policy Innovation". American Journal of Political Science, v. 24, no 4, pp. 715-729, 1980.

\section{Notas}

[i]Programa Saúde da Família, Bolsa Escola e Planos Municipais de Saneamento.

[ii]Para uma revisão da literatura com ênfase no papel das ideias ver Faria (2003).

[iii]Até 2014, 695 municípios adotaram a política. Porém, no banco de dados fornecido pela SPM-PR (2014), os anos de criação dos OPM só estavam disponíveis para 454 casos. Com exceção dos determinantes externos, as demais hipóteses elaboradas e seus respectivos testes serão relativos a estes 454 casos e não se referirão aos outros 241 municípios em que não se sabe o ano de criação do OPM. Esta medida metodológica foi adotada em razão do ano da criação da política representar um fator imprescindível para correlacionar as variáveis da pesquisa.

[iv]No ano de 2015, Roraima criou o OPM estadual.

[v]O site da Câmara dos Deputados, em 2002 informou que não houve dotação específica na Lei Orçamentária Anual para políticas para mulheres. Em 2003, foram executados pela SPM-PR 3,5 milhóes de reais. Em 2004 esse valor foi de 14,8 milhóes de reais. Isso demonstra que a criação de uma secretaria própria vinculada a Presidência da República, a partir da Lei № 10.683 de 2003, resultou em expressivo aumento de recursos para políticas para mulheres.

[vi] Vale ressaltar a publicação do inciso II da Portaria no 24 de 31 de janeiro de 2014: "Os editais priorizarão as propostas de convênios de origem dos entes públicos - estados e municípios -, tendo em vista o fortalecimento dos Organismos de Promoção de Políticas para as Mulheres - OPM" (Brasil, 2014).

\section{BY-NC-ND}

